\title{
Development of Electricity Sub Sector SDI: Case Study of KPLC, REA and KETRACO Kenya
}

\author{
Ekah Maina', Moses Murimi² \\ ${ }^{1,2}$ Dedan Kimathi University of Technology Institute of Geomatics, GIS\& Remote Sensing (IGGReS) Nyeri, P.O. Box 657-10100, Nyeri, \\ Kenya
}

\begin{abstract}
Energy is one of the most important ingredients that enable any country to realize major stride in development .Electricity is one of the leading form of energy. Electricity sub-sector in Kenya consists of several players who are responsible for regulation, generation, transmission, distribution and maintenance of electrical network in the country. The players deal with similar data sets in their operations but each operates independently in terms of collection and storage of both spatial and non-spatial data. This disconnected way of operation results to duplication of data collection efforts, duplication of projects, uninformed decision making and inconsistency in the data collected and stored. At the end of it all money and time usually go to waste. The main objective of this research was to develop a prototype for corporate spatial data infrastructure with the case study being Kenya Power and Lighting Company, Kenya Transmitting Company and Rural Electrification Authority to enhance spatial data sharing. The three organizations are involved in transmission and distribution of electricity in Kenya. The research started with establishing through questionnaires and interview if the need for data sharing existed among the three organizations and the data sets that each organization held. The research revealed that data sharing need existed and that data sharing would help in reducing duplication of projects, reducing the time taken for customers to be connected, save on resources used for duplicated data collection and also improve customer service quality. The methodology involved creating a personal data base for each organization which for the sake of research was assumed to be the organization's Geographical information system.Then the geoportal was installed and the interface customized to fit the theme of the research "KENYA ELECTRICAL NETWORK SDI Geoportal". In the geoportal users for all the organization were created and different roles assigned to them. Combination of tools were used which included Esri Geoportal server, Apache directory server and directory studio for establishing LDAP connection to the data base, Postgresql for the database, apache tomcat and ArcGIS. Finally, metadata for the sample data was created and published, the data was viewed on the geoportal after approval by the administrator. The system was configured such that only data published and approved by the administrator would be available on the geoportal to all users. Consultative meeting was held with the organizations stake holders and also questioners were used to establish the type of data each organisation held and if there was need for data sharing. The results were a working geoportal with all capabilities and interactive web map embedded on map viewer. In conclusion the research showed that there was need for data sharing among the three organizations. The main recommendation was that the model could be adopted by the whole energy sector and other related sector which could eventually to the realization of the Kenya National Spatial Data Infrastructure.
\end{abstract}

Keywords: Spatial Data Infrastructure, Geoportal, Electrical Sub-sect, Distribution

\section{Introduction}

\subsection{Back Ground}

Kenya development agenda which is anchored in the vision 2030 identifies electrical energy as one of the key infrastructural enabler for development .Electricity subsector in Kenya is made up by several organizations as shown in figure 1.Most of these players have overlaps in their operations .Especially the ones the ones that are involved in transmission and distribution of electricity. Thus they use similar spatial and non-spatial datasets .Currently each organization operate independently in terms of data collection and storage, there is no existing established data sharing platform.

Spatial Data Infrastructure (SDI) provides a framework of standards, policies, data procedures and technology that support effective coordination and sharing of spatial information [1].Web mapping and portal technology have made the data sharing achievable. 


\section{International Journal of Science and Research (IJSR) \\ ISSN (Online): 2319-7064 \\ Index Copernicus Value (2013): 6.14 | Impact Factor (2014): 5.611}

sets .Currently the organizations do not have a system for data sharing. This has resulted in problems of duplication of projects, data collection efforts, uninformed decision making and data inconsistency. This causes waste of money and time.

The demand for electricity in Kenya has gone up tremendously with the number of customers rising from 686,195 customers in June 2004 to 3,610,340 by June 2015.The Kenya Government has also set a target of $70 \%$ electricity access by 2016 and a $100 \%$ by 2020 .To achieve this the three organisations need to read from the same spatial and non-spatial page.

The man objective of this study was to develop a corporate Spatial Data Infrastructure (SDI) prototype which was achieved through a geoportal. The geoportal enabled creation of users and rights, publishing of Meta data and spatial resources. The research also sort to establish if the need of data sharing existed among the organizations, the data sets and their format each held and how data sharing would be achieved.

\subsection{Study Area}

For the purpose of developing the spatial data infrastructure, part of Muranga and Kiambu counties were selected the area of study. Kiambu County is a one of the counties in the former Central Province of Kenya. It lies between latitudes $1^{\circ} 10^{\prime}$ South and, Longitudes $36^{\circ} 50^{\prime}$ East .The County is bounders Nairobi, Murang'a, Machakos and Nyandarua counties.It occupies a total area of 2,243 square km.Murang'a County is one of the five counties in Central region of the Republic of Kenya. It lies between latitudes $0^{\circ}$ $34^{\prime}$ South and Longitudes $36^{\circ} \mathrm{s}$ East and $37^{\circ} 27^{\prime}$ East. The county occupies a total area of $2,558.8 \mathrm{Km} 2$.

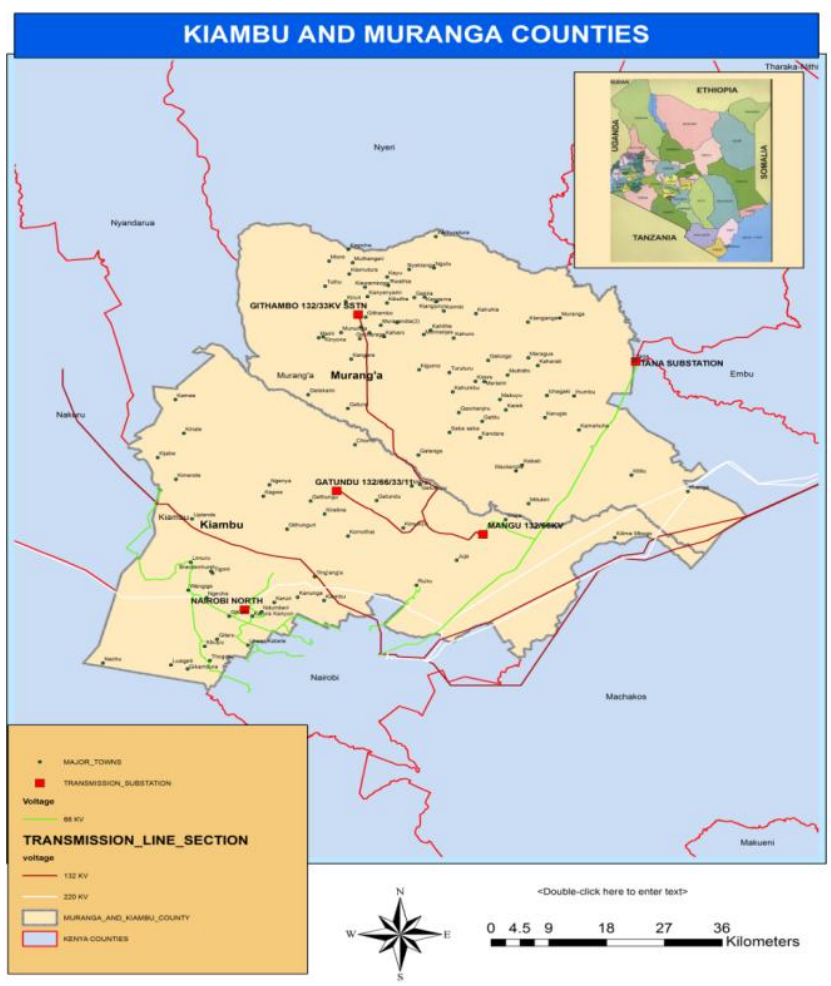

Figure 2: Parts of Kiambu and Murang'a County
GIS can effectively manage information on distribution of electricity to customers and information describing the attributes of each customer such as location and electricity use. Electric power companies are already finding GIS very useful in management of distribution networks [2].

An SDI is more than a single data set or database; it hosts geographic data and attributes, sufficient documentation (metadata), a means to discover, visualize, and evaluate data (catalogues and web mapping), and some method that provides access to the geographic data. Furthermore, there are additional services or software to support application and integration of data [3].

In Kenya very little has been achieved in the implementation of national Spatial Data Infrastructures. The Development of KNSDI and implementation in Kenya is ad hoc and fragmented. Comparing it with other African countries the development is average [4].

The availability of GIS technology and data has resulted in the ease of data exchange and integration across organizations; this in turn stimulates inter-organizational partnerships in spatial data sharing [5]. In this multiparticipant setup, public and/or private organizations at local, regional and national level are jointly involved in data acquisition and database development for a common purpose [5].In Kenya research by [6] showed that there was little or no cooperation between organizations on spatial data sharing. They proposed a prototype of Nairobi County Council where the players in the county council would access data from the portal.

\section{Methodology}

The methodology was carried out as shown

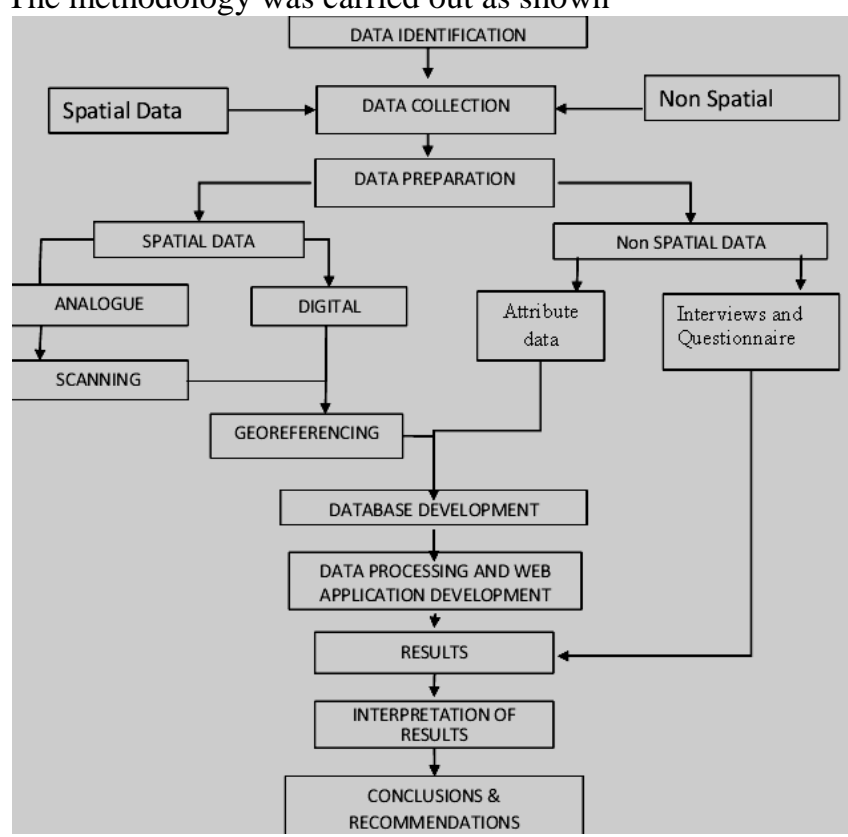

Figure 3: General Overview of the Methodology

\subsection{Data Collection}

Non-spatial data was collected through questionnaires and consultative meeting with the various mapping sections. The 


\section{International Journal of Science and Research (IJSR) \\ ISSN (Online): 2319-7064 \\ Index Copernicus Value (2013): 6.14 | Impact Factor (2014): 5.611}

main purpose was to establish whether data sharing was necessary and also identify the type of data set each organization held. Spatial data and associated attribute were obtained from the organizations' drawing offices and land offices. Data was processed and converted to Esri's shape files format using ArcGIS 10.1 software as shown in the figure below.

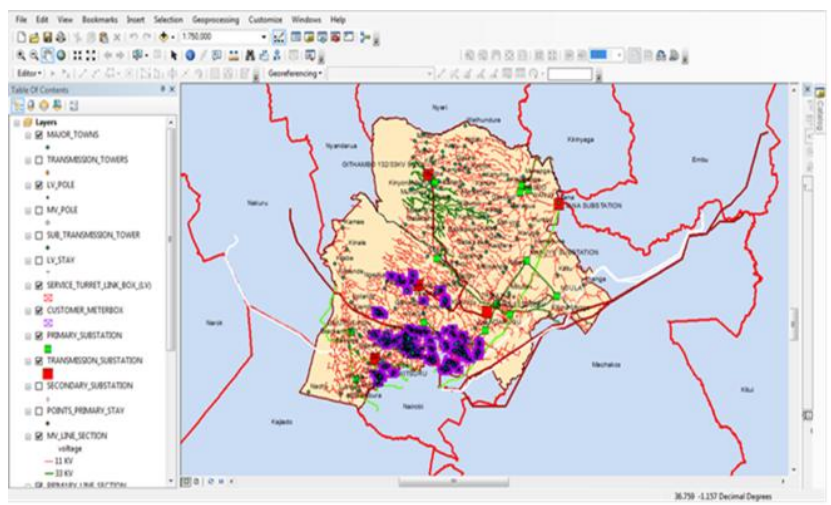

\subsection{Creation of Geo-databases}

A geodatabase was created for each organization by creating a .mdb file using arc catalog window in arc map. Data for each organization was uploaded into the respective geodatabase.

\subsection{Installation and configuration of the Geoportal}

The installation and configuration followed steps as shown in the figure below

Figure 4: Data Layers created in ArcMap

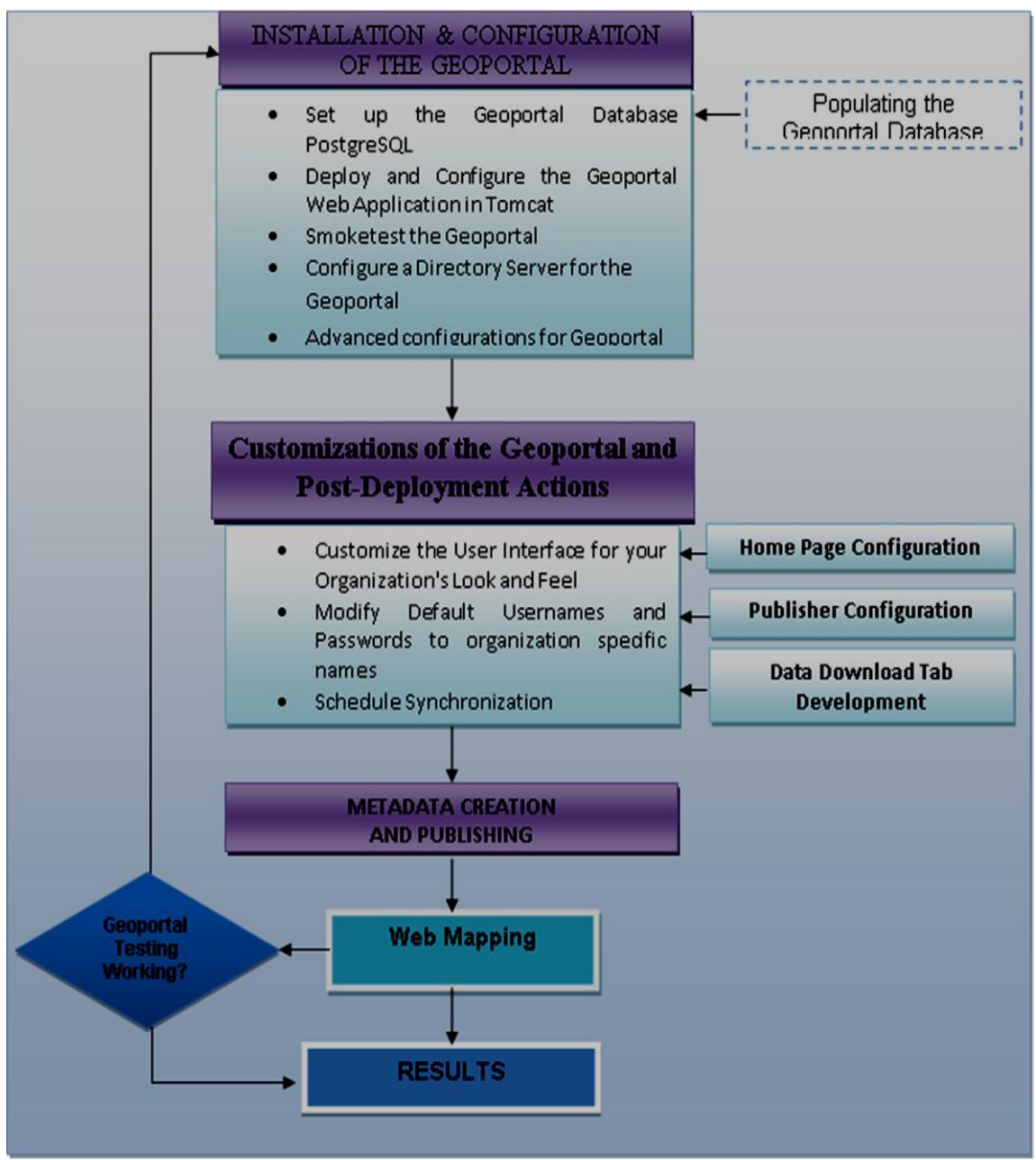

Figure 5: Installation and Configuration Geoportal

\subsubsection{Setting up Geoportal Database in PostgreSQL}

PostgreSQL database was set up by setting up the database permissions and creating database schema, through execution of database scripts. The database was streamlined to simplify installation and operation of the geoportal. The streamlining opened up the postgres database connections from the host computer only allowing it to connect via a TCP/IP. The geoportal web application was deployed by deploying the geoportal, War file, and then configuring its property file gpt.xml. These was to ensure successful communication between the web applications and other system components. 


\section{International Journal of Science and Research (IJSR) \\ ISSN (Online): 2319-7064 \\ Index Copernicus Value (2013): 6.14 | Impact Factor (2014): 5.611}

\subsubsection{Smoke testing the Geoportal}

After web application installation smoke testing was carried out to ensure successful functioning of the geoportal.Geoportal advance configuration was carried by carrying out settings in the gpt.xml file and adjusting the file to enable it support additional functionality. Afterwards geoportal web client software was installed to enable users discover and use GIS resources. A client tool for arc catalog was installed to allow users publish meta data easily.

\subsubsection{Home Page and Directory Server Configuration}

The user interface (home page) was configured to suite the theme of the research. "Kenya electrical Network SDI". Light Weight Directory Access Protocol (LDAP) connection to enable access and control of users. After installation of server directory, directory server client and defining a connection between the client and the server the major client's rights were created i.e. administrator, publisher and general user. User rules were set, publisher access requested and user profiles were created .User specific functionality such as maintaining profiles, saving, search, publishing and different user accounts were created

\subsubsection{Metadata form configuration}

Meta data editor form was configured using definition.xml file and elements fitting the geoportal were chosen to make a template. The meta data $\mathrm{xml}$ files for the elements identified and added and meta data interface for all profiles was designed and all elements grouped in order. Obligation rules were also set to enable users identify mandatory requirements. User accounts were created and different profiles i.e. publisher, administrator with different rights were created.

\subsubsection{Creating metadata and publishing resources}

Metadata for the resources to be published were created in different ways, Manually, this option was to be used when the user lacked existing metadata to upload or was unable to register resource on the network.Metadata was created by the administrator/publisher login then on administration tab selected add link option,then use dedicated editor was selected from the dropdown options on add page. The meta data form was filled, validated, saved and submitted and submitted to geoportal for publishing. The second method of creating metadata was through a geoportal extension publish client on the ArcGIS tool bar.The folder whose metadata was to be published was selected on the arccatalog tree .By clicking the Publish Client button an interface with fields to be filled appeared .After filling the form the metadata was published against the geoportal standards.

\section{Results and Discussion}

\subsection{Questionaires and Consultative meeting}

Analysis carried out on the response of the questionnaire by different respondents established that the three organisations held data on electrical network and some land information. The data sources were both primary and secondary where GPSs and total stations were used to collect the data from the field.The data was digitally stored in personal computers it is only Kenya power and lighting company that had a GIS which was in its formative stages. The response from the questionnaire established that the three organisations used similar spatial data sets ,but these data sets are not easily accessible by the other organisations and when accessed the data sets are in different formats. The sharing is hard since there are no set data sharing standards. All the respondents unanimously agreed that there was need for the three organisations to share data as this will help improve their operations and the quality of work.

Table 3:1 Need for data sharing results

\begin{tabular}{|c|c|c|c|c|c|c|c|c|c|c|c|c|c|c|c|c|c|c|c|c|c|c|c|c|c|c|c|c|c|c|}
\hline & \multicolumn{30}{|c|}{ ELECTRICAL SUB SECTOR DATA SHARING NEED QUESTIONNAIRE FINDINGS } \\
\hline & & & & & & & & & & & & & & & & & & & & & & & & & & & & & & \\
\hline 3 & Question & \multicolumn{3}{|c|}{1} & \multicolumn{3}{|c|}{2} & \multicolumn{4}{|c|}{3} & \multicolumn{4}{|c|}{4} & \multicolumn{2}{|r|}{5} & & 6 & & 7 & \multicolumn{2}{|c|}{8} & \multicolumn{3}{|c|}{9} & \multicolumn{2}{|c|}{10} & \multicolumn{2}{|c|}{11} \\
\hline 4 & Response & C & $B$ & C & A & B & C & A & B & C & D & A & B & C & D & A & B & A & $B$ & A & $B$ & A & B & A & B & C & A & $B$ & A & B \\
\hline 5 & KPLC & 0 & 0 & 20 & 0 & 0 & 20 & 2 & 0 & 1 & 17 & 0 & 4 & 1 & 15 & 20 & 0 & 20 & 0 & 0 & 20 & 0 & 20 & 0 & 0 & 20 & 20 & 0 & 20 & 0 \\
\hline 6 & REA & 0 & 0 & 6 & 0 & 0 & 6 & 6 & 0 & 0 & 0 & 0 & 6 & 0 & 0 & 0 & 6 & 6 & 0 & 0 & 6 & 0 & 6 & 4 & 1 & 1 & 6 & 0 & 6 & 0 \\
\hline 7 & KETRACO & 0 & 0 & 3 & 0 & 0 & 3 & 0 & 0 & 3 & 0 & 0 & 3 & 0 & 0 & 0 & 3 & 3 & 0 & 0 & 3 & 0 & 3 & 0 & 1 & 2 & 3 & 0 & 3 & 0 \\
\hline 3 & TOTAL & 0 & 0 & 29 & 0 & 0 & 29 & 8 & 0 & 4 & 17 & 0 & 13 & 1 & 15 & 20 & 9 & 29 & 0 & 0 & 29 & 0 & 29 & 4 & 2 & 23 & 29 & 0 & 29 & 0 \\
\hline
\end{tabular}

The consultative meeting revealed that the organizations held similar data sets which are stored in different formats. The participants agreed that there was an urgent need for organisations to share spatial data.

\subsection{Geo-databases and PostgreSQL database}

Data obtained from different sources was cleaned and processed and personal databases for all the three organizations were created and populated with data.

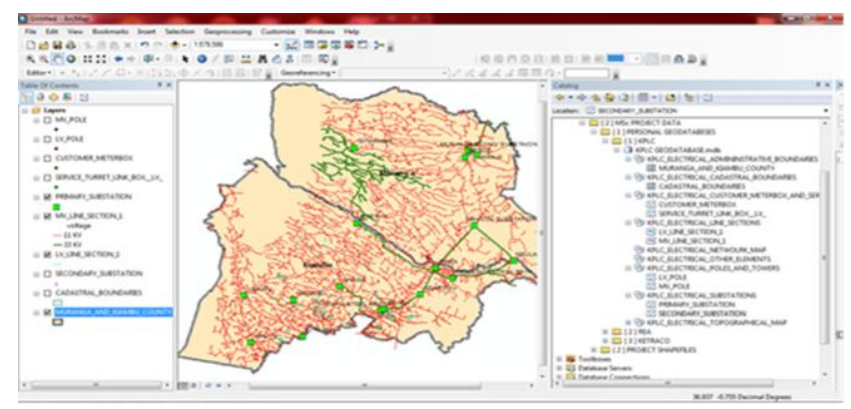

Figure 5: Geodatabase

The postgre SQL database was installed for the purpose of storage of all the data to be published and also the users. 


\section{International Journal of Science and Research (IJSR) \\ ISSN (Online): 2319-7064}

Index Copernicus Value (2013): 6.14 | Impact Factor (2014): 5.611

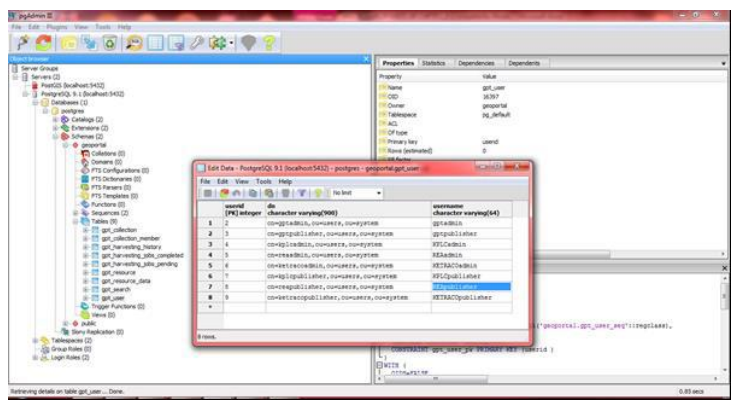

Figure 6: Postgre SQL Database

\subsection{Geoportal interface}

The Kenya electrical network geoportal interface was installed and customised to fit the theme After which data from the organisations geodatabases was published with their meta data.After approval by the administrator the data was available for all users the data was hosted in URL simoa.me.ke
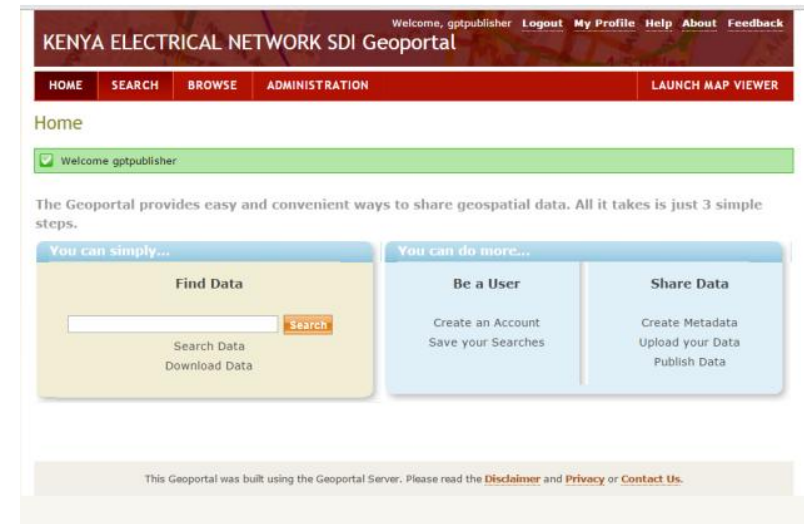

Figure 7: Geoportal Home Page Interface

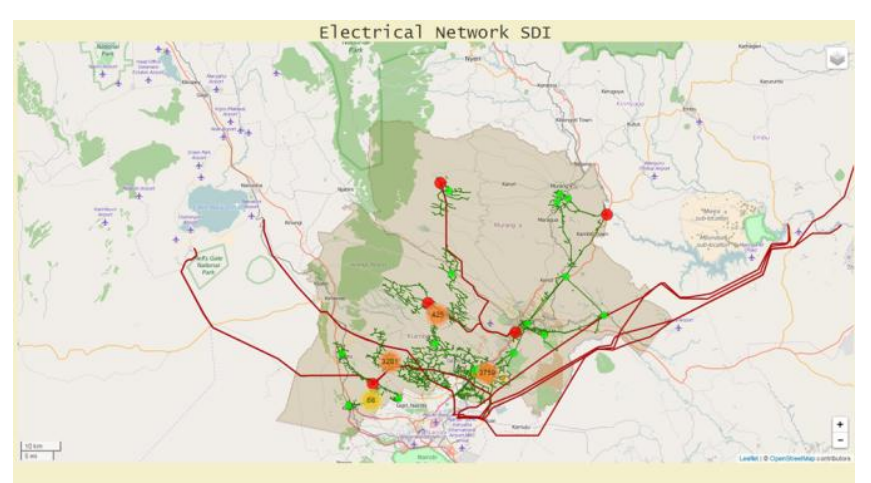

Figure 8: Data published in the geoportal.

\section{Conclusions}

The research shows there is need for data sharing between the electricity sub sector organizations involved in transmission and distribution of electricity. The Geoportal designed will help in addressing this need for data sharing. This will help in minimising duplication of projects, data collection effort and improve on customer services quality. The geoportal will help in improvement of quality of mapping by adhering to set standards before publishing their data in the geoportal.

\section{Recommendations}

The research was limited to a few organizations and also a limited geographical area. Future research should incorporate more organizations that relate to electricity subsector and other related organizations.The three organizations should take into consideration adopting the geoportal and expanding it to cover the whole country spatially and also improve the interface like sharing the projects each organization is undertaking. This will help them and the government meet the electricity access target of $100 \%$ by 2020 .

\section{References}

[1] Onah, C. C. (2009). Spatial data infrastructures model for developing countries: A case study of Nigeria.

[2] Yadav, S. K. (2013). GIS in Power Sector Management. International Journal of Engineering, 6(6), 759-766.

[3] Infrastructures, D. S. D. (2004). The SDI Cookbook. GSDI/Nebert.

[4] Okuku, J., Bregt, A., \& Grus, L. (2014). Assessing the Development of Kenya National Spatial Data Infrastructure (KNSDI). South African Journal of Geomatics, 3(1), 95-112.

[5] Nedovic-Budic, Z., \& Pinto, J. K. (1999). Understanding interorganizational GIS activities: A conceptual framework. URISA-Washington DC-, 11, 53-64.

[6] Mabeya, M., \& Waithaka, H. Developing a Geoportal for County SDI: Case Study of Nairobi County. International Journal of Science and Research 1965-1971

\section{Author Profile}

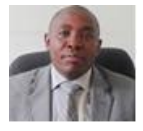

Moses Ngigi Senior Lecturer, Institute of Geomatics and GIS, Dedan Kimathi University of Technology, Nyeri, Kenya.He obtained his Bsc Surveying university of Nairobi, Kenya(1996).He obtained his Msc Photogrammetry and Geoinformatics from Stuttgart University of applied Sciences Germany(2001).He is a holder of phD in Geoenvironmental Sciences ,University of Tsukuba Japan.His interest in research are in GIS ,Community and Web GIS,Applied Geoinformatics for society and environment.

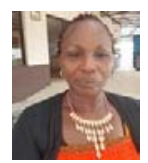

Ekrah Maina is a holder of diploma in land Survey (1998) from The Kenya polytechnic currently The Technical university of Kenya. She received her Btech,Geoinformatics in 2013 from the Technical university of Kenya. She is currently pursuing Msc in Geospatial Information Systems and Remote Sensing in Dedan Kimathi University of Technology.She Working as Geomatic Engineer in Kenya power and Lighting Company,Kenya. 